Discussion Paper No. 04-11

Concubinage or Marriage? Informal and

Formal Cooperations for Innovation

Werner Bönte and Max Keilbach

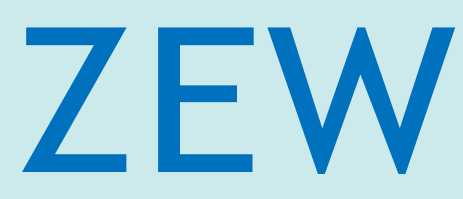

Zentrum für Europäische Wirtschaftsforschung $\mathrm{GmbH}$ Centre for European Economic Research 
Discussion Paper No. 04-11

\title{
Concubinage or Marriage? \\ Informal and \\ Formal Cooperations for Innovation
}

\author{
Werner Bönte and Max Keilbach
}

Download this ZEW Discussion Paper from our ftp server:

ftp://ftp.zew.de/pub/zew-docs/dp/dp0411.pdf

Die Discussion Papers dienen einer möglichst schnellen Verbreitung von neueren Forschungsarbeiten des ZEW. Die Beiträge liegen in alleiniger Verantwortung der Autoren und stellen nicht notwendigerweise die Meinung des ZEW dar.

Discussion Papers are intended to make results of ZEW research promptly available to other economists in order to encourage discussion and suggestions for revisions. The authors are solely responsible for the contents which do not necessarily represent the opinion of the ZEW. 


\section{Extended Abstract}

Research partnerships between innovating firms have attracted great political and academic attention during the past decade. Investigating this phenomenon, the focus of interest in the theoretical as well as in the empirical literature has generally been on formal arrangements of R\&D cooperation such as research joint ventures, informal cooperation modes have not been considered so far.

Using data from the first and second waves of the Mannheim Innovation Panel (MIP) we investigate which factors influence firms' propensity to engage into innovation cooperations with customers and suppliers.

The data-set makes evident that the number of firms that engage into informal cooperation for innovation is larger and informal cooperation is perceived as more important. On the basis of multinomial logit regressions, we obtain the following results. A firm's ability to protect its proprietary innovations by protection mechanisms (appropriability), like secrecy, complexity and lead time, tends to increase the probability of cooperating with vertically related firms. In contrast, our estimation results do not provide much empirical evidence in support to the hypothesis that (incoming) spillovers between vertically related firms do have a positive impact on firms' decision to cooperate. This extends the findings of previous work to informal cooperation. Moreover, we find that firms in industries with an intense development of new products and new markets (innovation dynamics) have a higher probability of cooperating formally and informally with customers and suppliers. Furthermore, firms that engage continuously in $R \& D$, hence firms with a larger absorptive capacity, engage into cooperation with higher probability. Firms who operate an $R \& D$ department and firms who are involved in costly $R \& D$ projects tend to cooperate formally rather than informally. 


\section{Das Wichtigste in Kürze}

Innovationskooperationen zwischen innovativen Firmen haben in der jüngeren Vergangenheit starke Aufmerksamkeit auf akademischer und politischer Ebene hervorgerufen. Dabei lag der Interessensschwerpunkt in der Regel auf formellen Typen von Innovationskooperationen, wie z.B. Forschungs Joint Ventures, informelle Kooperationsarten fanden in der Regel keine Beachtung.

Auf der Basis der ersten und zweiten Welle des Mannheimer Innovations Panel (MIP) untersuchen wir, welche Faktoren die Neigung von Firmen beeinflussen, Innovationskooperationen mit Kunden bzw. Zulieferern einzugehen.

Zunächst wird bei dem Datensatz deutlich, dass eine höhere Zahl von Firmen informelle Innovationskooperationen eingehen, gleichzeitig messen sie diesen Kooperationsformen höhere Bedeutung bei. Auf der Basis von multinomialen Logit Regressionen erzielen wir die folgenden Ergebnisse. Firmen, die in der Lage sind ihre Innovationen durch Schutzmechanismen oder -strategien (wie Komplexität der Technologie oder Geheimhaltung) vor schneller Imitation zu bewahren sind eher bereit Kooperationen einzugehen. (Empfangene) Wissenspillover haben keinen signifikanten Einfluss auf die Kooperationsneigung, wobei dies sowohl für formelle als auch (wie hier erstmals gezeigt werden konnte) für informelle Kooperationsformen gilt. Firmen, die sich in einer Branche mit einem hohen Anteil an neuen Produkten oder auf neuen Märkten betätigen kooperieren mit höherer Wahrscheinlichkeit sowohl formell als auch informell. Firmen, die dauerhaft FuE betreiben, also Firmen mit höherer Absorptionskapazität, kooperieren mit höherer Wahrscheinlichkeit. Firmen, die eine Forschungsabteilung betreiben und Firmen, die kostenintensive Forschungsprojekte betreiben, kooperieren eher formell und nicht ausschließlich informell. 


\title{
Concubinage or Marriage? Informal and Formal Cooperations for Innovation*
}

\author{
Werner Bönte Max Keilbach $^{\dagger}$
}

\begin{abstract}
Based on a sample of German innovating firms that contains information on formal and informal innovation cooperation between customers and suppliers, we state that firms perceive informal cooperation as being more important than formal cooperation modes. We then investigate the determinants of firms' decisions to engage into the respective cooperation modes. In line with previous empirical work, we do not find much empirical evidence for the relevance of incoming spillovers. In addition, our results suggest that this finding holds as well for informal cooperations. A firm's ability to protect its proprietary innovations, however, seems to be a key determinant of formal as well as informal cooperations. Furthermore absorptive capacity and the organizational structure of in-house R\&D play an important role. Another relevant driver of vertical cooperations are the innovation dynamics at the industry level. Firms who operate an R\&D department and firms who are involved in costly $R \& D$ projects tend to cooperate formally rather than informally.
\end{abstract}

JEL Classification: D21, L13, O31, O32

Keywords: R\&D Cooperation, Spillovers, Appropriability, Innovation.

\footnotetext{
*We would like to thank Reinhilde Veugelers, Gamal Atallah and Lars Wiethaus for very helpful comments. We are also grateful to the participants of the EARIE Conference in Madrid, the ZEW Workshop "Empirical Economics of Innovation and Patenting" in Mannheim and to seminar participants at the University of Hamburg.

${ }^{\dagger}$ Corresponding Author, Universität Hamburg, Von-Melle-Park 5, D-20146 Hamburg. boente@econ. uni-hamburg.de

${ }^{\ddagger}$ Max-Planck Institute for Research into Economic Systems, Kahlaische Str. 10, D-07745 Jena. This paper has been written while I was with the Centre for European Economic Research (ZEW) in Mannheim, Germany. I gratefully acknowledge financial support by the German Science Foundation (DFG) within research focus "Interdisziplinäre Gründungsforschung" under contract number STA 169/10-2.
} 


\section{Introduction}

Research partnerships between innovating firms have attracted great political and academic attention during the past decade. Investigating this phenomenon, the focus of interest in the theoretical as well as in the empirical literature has generally been on formal arrangements of R\&D cooperation such as research joint ventures (e.g. Cassiman and Veugelers, 2002; Kaiser, 2002; Tether, 2002, Miotti and Sachwald, 2003). ${ }^{1}$

However, other more informal types of cooperation for innovation, like informal communication between employees from cooperating firms, might play an important role in the exchange of technical knowledge. ${ }^{2}$ A research team of one firm, for instance, may ask researchers working in an R\&D department of another firm for technical information or providing themselves technical information to these researchers. In contrast to formal cooperations, the informal exchange of technical knowledge does neither imply coordination of $R \& D$ nor legally binding contracts. However, the empirical literature on the determinants of informal exchange of technical knowledge is scarce. ${ }^{3}$

Our sample of 730 innovating German firms (which is presented in detail in section 4) shows that informal cooperation is indeed an important mode of cooperation for innovation within the supply-chain. While roughly a fourth of all firms is not engaged in any cooperation, only 3\% engage in formal R\&Dcooperation with either supplier or customer, compared to roughly a third of firms which is engaged in informal cooperation or another third that cooperates formally and informally at the same time. Figure 1 illustrates these findings. Hence this suggests that most firms prefer informal cooperative arrangements (concubinage) while only a smaller fraction of firms prefers $R \mathcal{E} D$ marriage and these latter are typically engaged into informal cooperations as well. Moreover, the perceived importance to formal cooperation modes is low as compared to the rating of informal cooperation. ${ }^{4}$

\footnotetext{
${ }^{1}$ In these empirical studies cooperative arrangements are defined as 'active participation of partners in joint $R \& D^{\prime}$ which is a paraphrase for formal cooperations (coordination of $R \& D$ ).

${ }^{2}$ See Hagedoorn et al. (2000) for a taxanomy of research partnerships.

${ }^{3}$ A notable exception is the empirical study of Schrader (1991) where the determinants of the informal exchange of information between firms from the U.S. speciality steel and mini-mill industry are investigated.

${ }^{4}$ In the questionnaire, firms have been asked to give not only a quantitative asessment of their R\&D-cooperation modes but also to specify their perception of importance of these cooperation modes. While roughly $30 \%$ of all firms consider informal modes of cooperation as being of high or very high importance, only $9 \%$ or less do so for formal modes of cooperation, research joint ventures being the least important mode of R\&D-cooperation. See Harabi (1998) for similar observations.
} 


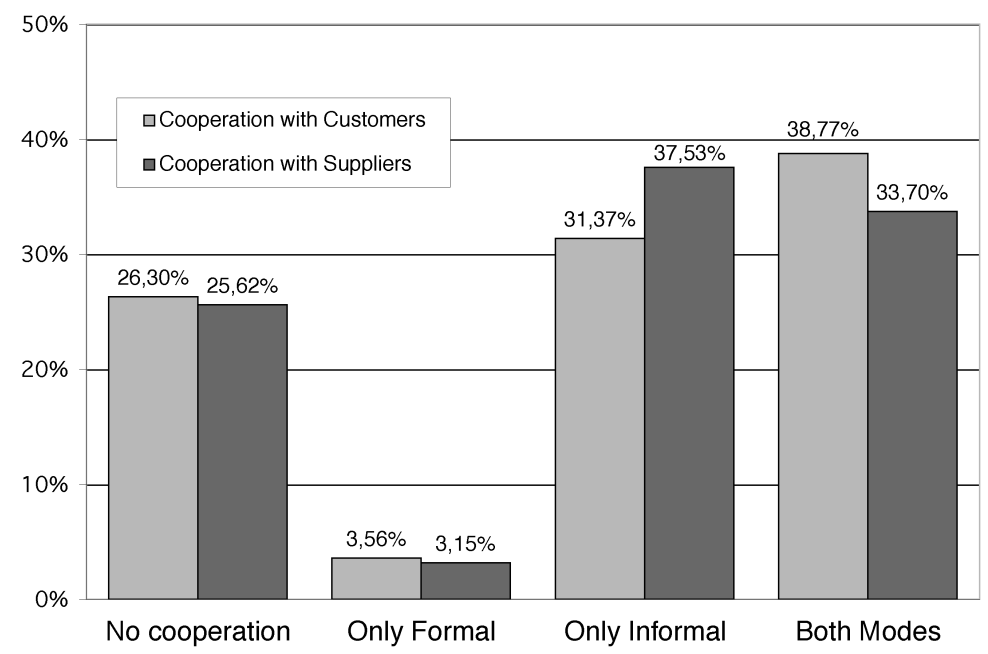

Figure 1: Firms' Choice of RED-Cooperation with Customers and Suppliers

The motivation of this paper is to investigate empirically the factors that influence the probability of firms to engage into formal and/or informal cooperation for innovation with vertically related firms. To do this we give a brief survey on the literature on research cooperations in the following section. In section 3, we set up the empirical model to be used. Data source and implementation are described in section 4 . Estimation results are presented and discussed in section 5. Section 6 draws the conclusions.

\section{Why should a firm engage into cooperations for inno- vation?}

Firms' incentives to form cooperations for innovation have been studied by scholars from different disciplines, like managerial literature, transaction cost approaches as well as industrial organization literature ${ }^{5}$. We do not aim to provide a comprehensive review of these different lines of literature. Instead, we identify five factors that can be expected to influence firms' incentives to engage into (formal and/or informal) cooperation and discuss their respective relevance on the basis of the existing relevant literature.

Knowledge Spillovers: Theoretical industrial organization literature suggests that Research Joint Ventures (RJVs) may be an efficient way of dealing with market failures in the innovation process, e.g. they allow firms to internal-

\footnotetext{
${ }^{5}$ See Hagedoorn et al. (2000) for a survey.
} 
ize knowledge spillovers (D'Aspremont and Jacquemin, 1988; Kamien et al., 1992; DeBondt, 1996). According to this literature an increase in the level of spillovers leads to an increase in a firm's probability of cooperating formally with competitors, given that the spillover level is high. ${ }^{6}$ Similar results are reported by authors who extended the analysis to $R \& D$ cooperations between customers and suppliers. Atallah (2002) and Inkmann (2001) introduce interindustry trade into the model of Steurs (1995) and show that vertically related firms do also have an incentive to coordinate their R\&D. ${ }^{7}$ Thus, one would expect that high knowledge spillovers lead to an increase in a firm's probability of cooperating formally with virtically related firms.

Existing empirical studies, however, do not provide empirical evidence for the hypothesis that knowledge spillovers from other firms do have a positive impact on formal R\&D-cooperations between customers and suppliers. Cassiman and Veugelers (2002), who have measured spillovers by the relevance of public information sources (e.g. patent information) report that the estimated coefficient of their spillover measure is statistically insignificant for vertical cooperations. Kaiser (2002) used the weighted sum of R\&D expenditures of firms belonging to other industries as a proxy for vertical spillovers and found no evidence for a positive influence of vertical spillovers on cooperation decision of firms in the German service sector.

In contrast to formal cooperation, the informal exchange of technical knowledge between cooperation partners does not allow for internalization of spillovers but generates itself voluntary knowledge spillovers between cooperating firms. Nevertheless, expected spillovers from cooperation partners may positively affect a firm's willingness to share information with its partner. A profit maximizing firm may choose to provide information to a cooperation partner in the expectation that it receives valuable information (spillovers) in return which may increase its profit. Thus, "reciprocity appears to be one of the fundamental rules governing information sharing"(Schrader, 1991, p. 154). Kultti and Takalo (1998) have shown that even competitors which can fully protect their technical knowledge have an incentive to share information if information sharing is not too asymmetric. Of course, a firm may benefit the more from the exchange of technical knowledge the more relevant the cooperation partners' technical knowledge is. The empirical results reported by Schrader (1991) for firms of the U.S. speciality steel and mini-mill industry confirm the relevance

\footnotetext{
${ }^{6}$ Then, the spread between profits from cooperation with competitors and profits from noncooperation is increased by an increase in spillovers.

${ }^{7}$ Steurs (1995) investigated cooperations between firms that belong to perfectly segmented industries.
} 
of reciprocity.

However, while reciprocity may be essential for the informal exchange of technical knowledge between competitors, the incentive to share knowledge without reciprocation might be much higher in buyer-supplier relationships. An upstream firm, for instance, may voluntarily create spillovers to customers - without reciprocation - in order to induce process and product innovations by the downstream firms which in turn may enhance the demand for the supplier's intermediate good (Harhoff, 1996). Thus, we would expect that knowledge spillovers from vertically related firms do increase the probability of informal cooperation if firms regard reciprocity as fundamental but have no influence if vertically related firms provide information without reciprocation.

Appropriability Conditions: While knowledge spillovers can be useful among cooperation partners they might be considered as unwanted leakage to third parties. A supplier may fear, for instance, that the customer transfers the technical knowledge shared by cooperation partners to the supplier's competitors. There is some evidence that such concerns exist in practice. Grindley et al. (1994, p. 744), for example, report that suppliers of semiconductor materials and equipment (SME) were concerned over sharing information with members of SEMATECH (the Semiconductor Manufacturing Technology Consortium) because they feared the disclosure of proprietary information to their competitors. In this case the leakage of technical knowledge may reduce the firm's returns drastically because it may allow its competitors to imitate its innovations immediately, i.e. it increases the returns to 'free-riding' by nonpartners. Consequently, Cassiman and Veugelers (2002, p. 1169) postulate that cooperating firms try to "maximize the incoming spillovers from partners and non-partners, while at the same time minimizing spillovers to non-partners."

Thus, appropriability conditions may have an influence on a firm's propensity to engage into informal as well as formal cooperation because it is very likely that knowledge sharing does occur in both modes of cooperation. In other words, it is not very likely that partners participate actively in joint $\mathrm{R} \& \mathrm{D}$ (cooperate formally) without sharing (voluntarily or involuntarily) any of their technical knowledge. The costs of sharing technical knowledge with vertically related firms - the decrease in a firm's rent expectation if the cooperation partner transfers the knowledge to competitors - are high if a firm's ability to protect its proprietary innovations is low and vice versa. Moreover, this ability may be viewed as a prerequisite for informal information trading because "proprietary know-how is only a subject for trading if free diffusion can be prevented" (von Hippel, 1987, p. 295). We therefore expect that appro- 
priability has a positive impact on the probability of cooperating formally as well as informally.

The results of empirical studies on the relevance of appropriability for formal cooperations are mixed. Cassiman and Veugelers (2002) found that firmspecific protection mechanisms (e.g. secrecy) increase the probability of cooperating formally with vertically related firms while industry-specific legal protection mechanisms (e.g. patents) have no impact. In contrast, Hernán et al. (2003) used a proxy that measures the effectiveness of patents in industrial sectors and found that the effect on cooperation is negative and statistically significant. However, the difference between the results may be explained by the fact that the cooperations investigated by Hernán et al. (2003) were mainly horizontal cooperations between competitors. ${ }^{8}$

Absorptive Capacity: Another important determinant for formal cooperation is a firm's engagement in RED. Many of the theoretical models dealing with spillovers and R\&D cooperation are based on the assumption that external knowledge is like 'manna from heaven'. ${ }^{9}$ In other words, firms may benefit from spillovers without doing any in-house R\&D which is not very plausible. According to Cohen and Levinthal (1989) firms need an absorptive capacity in order to assimilate and exploit external knowledge and this capacity is the result of the firm's own (in-house) R\&D efforts. Thus, it can be expected that the degree at which spillovers are useful for firms - which in turn may influence their propensity to engage into cooperations - is determined by their engagement in R\&D.

The result of empirical studies do not provide a conclusive answer to the question whether absorptive capacity is relevant for cooperations between vertically related firms. Fritsch and Lukas (2001) found that a firm's R\&D intensity has a statistically significant impact on the firm's decision to cooperate with customers and suppliers. The results reported by Tether (2002) for a sample of firms from UK suggest that a firm's engagement in R\&D has a positive effect on the probability of cooperating formally with customers and suppliers. In particular, continuous R\&D positively effects cooperations with customers but not those with suppliers while continuous R\&D combined with high $R \& D$ intensity has a positive impact on cooperation with suppliers but not on those with customers. However, using R\&D intensity as an explanatory variable may produce endogeneity problems since theoretical models predict

\footnotetext{
${ }^{8} \mathrm{~A}$ negative sign indicates that firms in industries with effective protection do not need to cooperate formally with their competitors in order to internalize spillovers.

${ }^{9}$ A notable exception is the study of Kamien and Zang (2000).
} 
that coordination of R\&D does affect firms' R\&D efforts and empirical studies provide evidence for this hypothesis (Kaiser, 2002; Colombo and Garrone, 1996). In contrast, Miotti and Sachwald (2003) and Cassiman and Veugelers (2002) report for firms from France and Belgium that permanent R\&D does not influence the firms' propensity to cooperate formally with vertically related firms. Hernán et al. (2003) using firm size to proxy absorptive capacity find for a sample of European firms indeed empirical evidence in favor of this argument. However, a firm's absorptive capacity can be expected to be a function of its R\&D activities rather than of the mere size.

Organizational Structure of R\&D: Furthermore, we argue that more qualitative aspects of a firm's R\&D activities such as the organizational structure of $R \mathcal{E} D$ within a firm may determine its ability to engage into formal cooperation. A high degree of organizational effort may be needed for instance to manage formal cooperations, like RJV's, joint development teams or formal R\&D cooperation. Running formal cooperations requires qualified personnel and produces overhead costs. Legally binding contracts have to be written and enforced or some researchers have to be assigned to long term joint $R \& D$ projects. One indicator for a high degree of organizational structure of R\&D within a firm is the existence of a RED department.

In contrast, the informal exchange of technical knowledge is less resource demanding. Von Hippel (1987, p. 300) postulates that the informal exchange of technical knowledge can be seen as an inexpensive and flexible form of cooperation which is a very effective form of cooperation if some of the partners do already have the know-how and when technical knowledge has a value because firms can keep it secret. Firms which perform R\&D continuously produce permanently new knowledge which can be exchanged with vertically related firms whereas it is not very likely that firms conducting R\&D on an occasional basis can do this.

Thus, we expect that the existence of a R\&D department has a positive impact on firms' probability of cooperating formally while firms without such a department but permanent R\&D may have a higher probability of cooperating informally.

Innovation Dynamics in Industries: Firms that belong to industries where innovation is characterized by the development of new products and markets rather than in the amelioration of existing ones may have a higher probability of cooperating because the development of new products may require cooperation with customers and suppliers. Suppliers that cooperate with their 
customers may do so, for instance, in order to reduce the risk associated with bringing a new product to the market (Tether, 2002, p. 951). Customers developing novel and very complex innovations may use research joint ventures, joint development teams or formal R\&D cooperations as a mean to coach their suppliers and to make sure that the supplied intermediate good or the supplied equipment meets the needs of the production of the new products. In a similar way the informal exchange of technical knowledge may be very helpful in very innovative environments. Therefore we expect that innovation dynamics in an industry is a relevant driver of formal and informal cooperative arrangements for innovation.

To sum up, so far, we have identified five main classes of variables that can be expected to have an influence on firms' propensity to engage into vertical R\&D cooperation: spillovers, appropriability, absorptive capacity, organizational structure of RED and industries' innovation dynamics. However, the list is probably larger: Vertically related firms may cooperate in order to share innovation costs of large scale R\&D projects (Banerjee and Lin, 2001) or to share the risks of innovation. Another motive of engaging into cooperation is to gain access to complementary knowledge. The availability of technical know-how within a firm may increase its attractiveness as a cooperation partner, hence a high complementarity of knowledge might increase the propensity to cooperate with that partner.

\section{Empirical Model}

Innovating firms which decide about cooperation with suppliers (customers) may choose to cooperate formally and/or informally or may choose not to cooperate at all. Hence, they may choose between four cooperation strategies. Profit maximizing firms choose their cooperation strategy according to its relative profit with respect to other cooperation strategies. A firm $i$ will opt to choose strategy $j$ if the expected profit of this strategy (denoted $\pi_{i j}$ ) is the maximum among the strategies.

$$
\pi_{i j}=\operatorname{Max}\left(\pi_{i 0}, \pi_{i 1}, \pi_{i 2}, \pi_{i 3}\right)
$$

The profit associated with each of these strategies is assumed to be determined by firm- and industry-specific factors $x$,

$$
\pi_{i j}=x_{i j} \beta+u_{i j}, \quad i=1, \ldots, N j=0, \ldots, 3 .
$$


where $\beta$ is a parameter vector, $u_{i j}$ is an error term and $i$ denotes the firm. The profit associated with each cooperation strategy is an unobservable latent variable. What can be observed, however, are the firms' choices of cooperation strategies. If strategy $j$ is chosen, we assume that this strategy is the most profitable strategy $\left(\operatorname{Prob}\left(\pi_{i j}>\pi_{i k}\right)\right.$ for all other $\left.k \neq j\right)$.

We assume that firms consider all four cooperation strategies simultaneously, which is a basic assumption of the multinomial logit (MNL) model and therefore justifies the use of this approach. Here, the non-cooperation strategy is treated in the same way as any other cooperation strategy. Alternatively, it would be possible to specify the cooperation decision as a sequential process where firms decide whether they cooperate or not at the first stage and decide about the mode of cooperation at second stage. However, a sequential process would imply that the profits of cooperation strategies at the second stage do not influence cooperation decision of the first stage which does not seem to be realistic. Hence, the MNL model seems to be the appropriate model.

Another basic assumption of the MNL model is that irrelevant alternatives are stochastically independent from each other (IIA-assumption), i.e. the odds ratios of any two cooperation strategies are independent of the probabilities of other cooperation strategies. Intuitively, the IIA assumption is not very plausible if firms view two strategies as similar rather than independent. Therefore, we tested for the validity of this assumption, test results are given in the appendix.

Assume that the $J$ disturbances of equation (2) are independent and identically distributed with type $I$ extreme distribution. Then, the multinomial logit model of cooperation choice can be written as follows (Greene, 2003, pp.719723)

$$
\operatorname{Prob}\left(Y_{i}=j \mid x_{i}\right)=\frac{e^{\beta_{j}^{\prime} x_{i}}}{1+\sum_{k=1}^{3} e^{\beta_{k}^{\prime} x_{i}}} \text { for } j=0, \ldots, 3, \beta_{0}=0 .
$$

where the variable $Y_{i}$ indicates a firm's choice of cooperation mode and one of the coefficient vectors is normalized to zero in order to achieve identification. The multinomial logit model implies that the log ratio of the probabilities for any two cooperation strategies $j$ and $k$ is given by

$$
\ln \left[\frac{P_{i j}}{P_{i k}}\right]=x_{i}^{\prime}\left(\beta_{j}-\beta_{k}\right)=x_{i}^{\prime} \beta_{j} \text { with } \beta_{k}=0 .
$$

This means that the estimates of $\beta_{j}$ reflect the marginal effect of a change in an explanatory variable $x_{i}$ on the log-odds ratio of the cooperation strategy $j$ and the baseline strategy $k$. Note, that sign and magnitude of this coefficient are not necessarily identical with the marginal effect of a change in $x_{i}$ on probability 
$P_{i j}$. The latter can be calculated as follows

$$
\frac{\partial P_{j}}{\partial x_{i}}=P_{j}\left[\beta_{j}-\sum_{k=0}^{3} P_{k} \beta_{k}\right]=P_{j}\left[\beta_{j}-\bar{\beta}\right] .
$$

Estimates of the marginal effects of changes in explanatory variables on logodds ratios as well as on probabilities of individual cooperation strategies will be presented in section 5. Let us now present the data on which our analysis is based.

\section{Data}

The data-set used in this paper is based on the first and the second wave of the Mannheim Innovation Panel (MIP) in 1993 and 1994. The first wave was part of the Community Innovation Survey (CIS) of the European Commission. This data was collected by the Zentrum für Europäische Wirtschaftsforschung (ZEW) and the Institut für angewandte Sozialforschung (infas). We make use of both samples because the questionnaires contain different areas of information which are needed to test the hypotheses of the following section. The questionnaire of the second wave contains questions related to different modes of cooperation for innovation while the questionnaire of the first wave contains information on apropriability conditions, relevance of external knowledge sources as well as obstacles to innovation.

The original samples consist of 2860 (first wave) and 3065 (second wave) firms. However, the question concerning the different modes of cooperation had not been answered by firms which had not introduced product/process innovations or had not conducted activities to develop such innovations during the period from 1991 to 1993 . Thus, our study is restricted to the innovating firms. Moreover, we have merged both samples at the cost of a reduction of the number of observations. Due to missings the number is further reduced to 730 firms.

Formal and informal cooperation: In the second wave of the MIP, cooperation between customers and suppliers were at the center of interest. Therefore the questionnaire does not provide information about cooperations with competitors, for instance. The surveyed firms were asked the following question separately for cooperations with customers and suppliers: "Cooperation with customers (suppliers) might have a special importance for your innovative activities. Which of the following modes of cooperation with customers (suppliers) have you had in your firm/line of business in the years 1991-1993." 
Possible answers were: "joint ventures, joint development teams, formal R\&D cooperation, R\&D orders and informal exchange of technical knowledge."

Joint ventures, joint development teams and formal R\&D cooperation are formal modes of cooperation since firms $R \& D$ activities are coordinated and they are typically based on contractual agreements. $R \& D$ orders are, in a strict sense, market transactions rather than cooperations and we therefore exclude them from the further analysis. Although not reported here, we have examined whether the four remaining modes of cooperation are related to each other. Our results suggest, that these modes of cooperation can be reduced to two subgroups: formal and informal modes of cooperation. The same result is reported by Harabi (1998). In the further empirical analysis the variable reflecting informal cooperation with customers (suppliers) takes a value of 1 when firms reported that they had informal exchange of technical knowledge with their customers (suppliers) and 0 otherwise. The variable reflecting formal cooperations with customers (suppliers) takes a value of 1 when firms reported that they had joint ventures and/or joint development teams and/or formal $R \& D$ cooperation with their customers (suppliers) and 0 otherwise.

Table 1 shows the share of firms in the total number of cooperating firms classified according to different modes of vertical R\&D-cooperation as well as different cooperation partners. We have computed the shares for the total sample (second wave) as well as for our merged sample. As can be seen from the upper half of the table, a minority of all cooperating firms (less than 10\%) is engaged into formal R\&D-cooperation alone, while roughly $40 \%(50 \%)$ choose to cooperate purely informally with customers (suppliers). The other cooperating firms engage in both, formal as well as informal cooperation. Thus, $90 \%$ of the cooperating firms have informal cooperations.

The lower half the table 1 reports on the shares of cooperations with customers and suppliers for formal and informal cooperations separately. As can be seen, 90 percent of the firms are engaged into an exchange of technical knowledge with both, customers as well as suppliers. The picture is somewhat different, however, for formal R\&D cooperations. Here, $26 \%$ of the firms cooperate exclusively with customers and $15 \%$ exclusively with suppliers while merely 59 percent of the firms having formal cooperation with both, customers and suppliers.

Note, that the shares presented in table 1 are very similar for the total sample and our merged data-set. This suggests that our data-set represents the distribution of cooperating firms' choice of cooperation modes and cooperation partners quite well. Indeed, a $\chi^{2}$-test confirms that the shares in the sample do not differ significantly (at $\alpha=0.01$ ) from those in the complete data-set. 
Table 1: Shares of firms with certain cooperation mode in total cooperations

\begin{tabular}{lcccc}
\hline & $\begin{array}{c}\text { Customers } \\
\text { (total) }\end{array}$ & $\begin{array}{c}\text { Customers } \\
(\text { sample) }\end{array}$ & $\begin{array}{c}\text { Suppliers } \\
\text { (total) }\end{array}$ & $\begin{array}{c}\text { Suppliers } \\
\text { (sample) }\end{array}$ \\
Formal & $8.2 \%$ & $4.8 \%$ & $6.2 \%$ & $4.2 \%$ \\
Informal & $43.7 \%$ & $42.6 \%$ & $52.2 \%$ & $50.5 \%$ \\
Both & $48.1 \%$ & $52.6 \%$ & $41.6 \%$ & $45.3 \%$ \\
\hline & Formal & Formal & Informal & Informal \\
& (total) & $($ sample) & (total) & (sample) \\
Customers & $26.1 \%$ & $26.1 \%$ & $4.1 \%$ & $3.0 \%$ \\
Suppliers & $15.6 \%$ & $15.1 \%$ & $5.6 \%$ & $4.5 \%$ \\
Both & $58.3 \%$ & $58.8 \%$ & $90.3 \%$ & $92.5 \%$ \\
\hline
\end{tabular}

Note: The number of cooperating firms in our sample is 730 while the number of firms in the total sample (second wave) is 3065 .

Knowledge spillovers: The first spillover measure used in this study is a measure proposed by Cassiman and Veugelers (2002). The firm-specific measure of incoming spillovers is based on the beliefs of the firm's management about the importance of publicly available information for the firm's innovation process: patent information, specialist conferences and journals. This measure avoids the difficulties of constructing spillover measures by "jointly measuring the extent of the pool of relevant knowledge and its productivity for the firm's innovation process" (Cassiman and Veugelers, 2002, p. 1171). ${ }^{10}$ However, the spillover measure proposed by Cassiman and Veugelers may capture spillovers from public information sources but it is not a specific indicator for the spillovers between customers and suppliers. It may reflect spillovers from competitors, vertically related firms, other firms, universities as well as public research institutes. Hence, we call it the generic spillover measure.

We introduce additional spillover measures which we call specific spillover measures because they reflect the knowledge flows from customers and suppliers. These measures are based on the beliefs of the firm's management about the importance of customers and suppliers as information sources for the firm's innovation process. In the questionnaire firms rated the importance of (1) customers, (2) suppliers of intermediate inputs and (3) suppliers of equipment on a 5-point scale. We have computed the relevance of suppliers by summing the scores of answers to questions (2) and (3). We acknowledge that these measures may not only capture voluntary and involuntary spillovers from cus-

\footnotetext{
${ }^{10}$ Alternatively, other firms' R\&D capital stocks may be used as spillover measures. However, such measures require the calculation of firm-(industry-) specific R\&D capital stocks and the computation of weights to aggregate them. See Griliches (1992).
} 
tomers (suppliers) but may also reflect knowledge flows that arise from market transactions, like R\&D orders or licensing. The score of each indicator is re-scaled to a number between 0 and 1 . We apply this form of re-scaling to all variables which are based on qualitative answers.

Appropriability: Following Cassiman and Veugelers (2002) we use two measures to capture appropriability conditions, one is firm- the other is industryspecific. In the first wave of the MIP firms rated the effectiveness of protection mechanisms separately for product and process innovations on a 5-point scale. Appropriability conditions are represented by two groups of mechanisms. The first group are legal protection mechanisms: (1) patents, brand names and copyright. The second group are strategic protection mechanisms: secrecy, complexity and lead time in commercialization. The answers have been aggregated to variables appropriability and legal protection. Legal protection enters the estimation as an industry-level variable (2-digit NACE). because it is likely that this protection mechanism is industry- rather than firm-specific. Firm-specific appropriability is measured by strategic protection mechanisms.

Absorptive capacity and organizational structure of R\&D: We use two variables to describe absorptive capacity and the organizational structure of firms' $R \& D$ : One that indicates whether a firm performs R\&D continuously and one that indicates the existence of an R\&D-department, both being coded as binary variables. These variables continuous $R \mathcal{E} D$ and existence of $R \mathcal{E} D$ Department are not identical. While all firms in our data-set with a R\&D department perform R\&D continuously, more than one third of firms that perform R\&D continuously do so without a R\&D department.

Innovation dynamics on industry level: In the questionnaire of second wave of the MIP firms have estimated the share of various categories of innovation expenditures in total innovation expenditures. Two categories were expenditures for a) test production, pilot projects, product design (not R\&D) and b) market tests and market development costs (without cost for establishing a sales network). The sum of both shares reflects the intensity of development of new products and new markets. We take the mean of this measure by industry level (2-digit NACE) as a proxy for innovation dynamics in an industry.

Innovation cost, innovation risk and complementarities: In the first wave of the MIP one area of information concerned the factors hampering innovation. Firms rated the relevance of various factors hampering their innovative 
activities on a 5-point scale. Out of 13 possible answers we have chosen two for the construction of an indicator variable of innovation risk: a) innovation risk too high and b) difficulties in controlling innovation costs. To construct an indicator for innovation costs we used the following answers: c) low return to innovation expenditures because of high costs of the innovation and d) low return to innovation expenditures because of lasting amortization duration. In order to construct an indicator variable for complementarities we used the answer: e) lack of technological information. The measure of complementarities is 1 minus the re-scaled score of this answer.

Firm specific characteristics: Other firm-specific control variables are firm size, measured as the logarithm of the number of employees and a dummy that takes the value one if a firm is located in Eastern Germany and 0 otherwise. The first one controls for effects of firm size which in previous studies have found to be relevant for cooperation (e.g. Cassiman and Veugelers, 2002, Hernán et al., 2003, Kaiser, 2002). The second accounts for idiosyncratic shocks that occurred through the transition process in Eastern Germany at the time of observation. ${ }^{11}$

\section{Results}

In this section we will present the marginal effects of changes in explanatory variables on log-odds ratios and on probabilities of individual cooperation strategies (see equations 4 and 5) obtained from separate estimations of the MNL model for cooperations with customers and suppliers.

However, let us first discuss potential endogeneity problems that may occur in the estimation process. Above, we have argued that specific spillovers from vertically related firms may influence the firms' decision to cooperate. However, a reverse effect of formal and informal cooperations on incoming spillovers may also exist since firms may form informal and formal cooperations in order to increase incoming knowledge flows. Thus, firms may rate customers or suppliers as important external sources of information because formal and/or informal cooperations are important channels for the transfer of knowledge between vertically related firms. The data used in this study

\footnotetext{
${ }^{11}$ In the second wave of the MIP firms reported on their vertical cooperations during the years from 1991 to 1993. At that time, a transformation process took place in Eastern Europe and research and cooperations networks in Eastern Germany changed drastically or vanished. Therefore, firms located in Eastern Germany can be expected to have a lower propensity to cooperate formally and informally.
} 
do not contain information about the degree of voluntary knowledge sharing. The only information we have is that there is voluntary knowledge sharing in informal cooperations but we can not say whether it occurs in formal cooperations. However, it is very likely that our measures of specific spillovers are endogenous with respect to cooperation. Therefore, we follow Cassiman and Veugelers (2002) and make use of a two step estimation procedure. The first step is the regression of the endogenous variables on instrument variables. The latter are those variables which are exogenous by assumption. The second step is the estimation of the MNL model using the predicted values of the potentially endogenous variables as explanatory variables. ${ }^{12}$

First, we have estimated the MNL model with the four categories 'no cooperation', 'informal cooperation', 'formal cooperation' and 'both modes of cooperation'. However, a Wald test of whether the latter two categories 'formal cooperation' and 'both modes of cooperation' can be combined suggest that this is the case. Thus, we have proceeded with the remaining three choice categories. Further Wald test reject the Null hypothesis that these categories can be further collapsed indicating that significant differences between these cooperation strategies exist. ${ }^{13}$ Thus, we will analyze three cooperation strategies, namely 'no cooperation', 'informal cooperation', 'both modes of cooperation/formal cooperation'.

Next, we have tested the validity of the IIA assumption since it is essential for the appropriateness of the MNL model. We have employed a Hausmantype test provided by Hausman and McFadden (1984) which compares the estimated coefficients of a model using all three categories and a subset where one of the categories is excluded. If the IIA assumption holds, then the estimation of the restricted and the unrestricted model should provide similar estimates. The test results suggest that the null hypothesis of IIA cannot be rejected for cooperation with customers (see table 6 in the appendix). The same is true for cooperation with suppliers if the category 'both modes of cooperation' is excluded while the $\chi^{2}$-statistic is negative when the 'informal cooperation' category is excluded. Furthermore, we have performed an alternative test which has been proposed by Small and Hsiao (1985). The results of this test confirm that the IIA assumption is not violated.

\footnotetext{
${ }^{12}$ In contrast to Cassiman and Veugelers (2002) we do not treat generic spillovers, appropriability and continuous $R \& D$ as endogenous variables. It is unlikely, for example, that the effect of cooperation is strong enough to let firms switch from occasional to continuous R\&D. Nevertheless, we have performed second stage regressions for these variables but we have not found any evidence for endogeneity. To save space we will not report the results.

${ }^{13}$ See table 5 in the appendix.
} 
Table 2: Results of a multinomial logit estimation of the probaility of two classes of cooperation with customers and suppliers aginst no cooperation

\begin{tabular}{lrr|rr} 
Cooperation with & \multicolumn{2}{c}{ Customers } & \multicolumn{2}{c}{ Suppliers } \\
Cooperation mode & $(1)$ & $(2)$ & $(1)$ & $(2)$ \\
\hline Incoming Spillovers (generic) & -0.490 & 0.322 & -0.302 & 0.065 \\
& $(0.384)$ & $(0.576)$ & $(0.590)$ & $(0.913)$ \\
Incoming Spillovers* (specific) & 0.623 & 3.813 & 5.325 & 0.486 \\
& $(0.714)$ & $(0.083)$ & $(0.111)$ & $(0.895)$ \\
Appropriability & 0.992 & 1.488 & 1.228 & 2.072 \\
& $(0.032)$ & $(0.003)$ & $(0.008)$ & $(0.000)$ \\
Legal Protection on Industry Level & 0.023 & -1.453 & -0.514 & -0.340 \\
& $(0.993)$ & $(0.568)$ & $(0.839)$ & $(0.900)$ \\
Existence of R\&D-Dept. (0/1) & 0.276 & 1.057 & 0.446 & 1.163 \\
& $(0.380)$ & $(0.001)$ & $(0.156)$ & $(0.000)$ \\
Continuous R\&D (0/1) & 0.625 & 0.555 & 1.019 & 0.543 \\
& $(0.016)$ & $(0.046)$ & $(0.001)$ & $(0.123)$ \\
Cost of R\&D & -0.130 & 0.737 & -0.674 & 0.803 \\
& $(0.784)$ & $(0.158)$ & $(0.189)$ & $(0.157)$ \\
Risk of R\&D & 0.167 & -0.326 & -0.172 & -0.401 \\
& $(0.739)$ & $(0.535)$ & $(0.802)$ & $(0.593)$ \\
Complementarities & -0.315 & 0.179 & 0.220 & -0.024 \\
& $(0.456)$ & $(0.684)$ & $(0.600)$ & $(0.958)$ \\
Innovation Dynamics on Industry Level & 12.305 & 12.952 & 13.696 & 13.211 \\
& $(0.011)$ & $(0.009)$ & $(0.004)$ & $(0.007)$ \\
Firm Size & 0.134 & 0.217 & 0.147 & 0.283 \\
& $(0.065)$ & $(0.003)$ & $(0.044)$ & $(0.000)$ \\
Firm is located in Eastern Germany $(0 / 1)$ & 0.532 & -0.117 & 0.260 & -0.455 \\
& $(0.026)$ & $(0.652)$ & $(0.432)$ & $(0.225)$ \\
Constant & -3.381 & -7.246 & -6.417 & -5.304 \\
& $(0.002)$ & $(0.000)$ & $(0.000)$ & $(0.006)$ \\
\hline Number of Observations & & 730 & & 730 \\
$\chi^{2}(24)$ & & 222.64 & & 241.18 \\
& & $(0.000)$ & & $(0.000)$ \\
Pseudo $R^{2}$ & & 0.1414 & & 0.1523
\end{tabular}

Cooperation modes: (1) informal cooperation; (2) formal cooperation and mixed cooperation modes.

*Variable Specific Incoming Spillovers results from an instrument variable estimation.

Values in brackets show probabilites of variables not to differ stochastically from zero (p-values). 
Estimation Results. The estimated coefficients presented in table 2 reflect the marginal effect of a change in the respective explanatory variable on the logodds ratios (see equation 4). Since we have chosen the category 'no cooperation' as the baseline category, a positive and statistically significant estimate of a coefficient implies that an increase in the respective variable leads to an increase in probability of cooperating relative to the probability of not cooperating. The first and the second column of the table contain the results for the 'informal cooperation' and the 'both modes of cooperation' categories of cooperations with customers. Columns three and four contain the results for cooperations with suppliers. According to the results of a likelihood ratio test, the hypothesis that the estimated slope coefficients of all explanatory variables are jointly zero can be safely rejected.

The estimated coefficients of the generic spillover measure are statistically insignificant for each category and they are jointly insignificant (see table 4 in the appendix for tests of joint insignificance). We find, however, some empirical evidence for a positive effect of specific spillovers on formal cooperation with customers. The estimated coefficient of this spillover measure is positive and statistically significant at the $10 \%$ level for the category 'both modes of cooperations'. The estimated coefficients of the appropriability measure are positive and highly significant whereas the estimated coefficients of the legal protection mechanisms measure are statistically insignificant. According to our estimation results the coefficients of four other variables, namely continuous $R \& D, R \& D$ department, firm size and innovation dynamics at the industry level are positive and statistically significant indicating a positive impact on the log-odds ratios. The results of separate Wald test for each of these variables which are presented in table 4 in the appendix confirm this.

The log-odds ratio of any two categories may increase because the nominator $\left(P_{j}\right)$ increases or the denominator $\left(P_{k}\right)$ decreases. Hence, the marginal effects of the explanatory variables on the probabilities of each cooperation strategy are more straightforward to interpret (see equation (5)). Therefore, we compute these marginal effects. Results are reported in table 3.

The results suggest that the probability of choosing the 'no cooperation' strategy is not influenced by incoming spillovers. Neither is the marginal effect of the generic spillover measure statistically significant nor is the marginal effect of specific spillover measure. It is, however, significantly reduced by an increase in a firm's appropriability. Thus, a high effectiveness of strategic protection increases the probability of cooperating with customers and suppliers. Moreover, the variables continuous $R \& D, R \& D$ department,firm size and innovation dynamics in industries have a negative and statistically significant 
Table 3: Results of two multinomial logit estimations of the probability of two classes of cooperation with customers and suppliers against no cooperation: marginal effects

\begin{tabular}{lrrr|rrr} 
Cooperation with & \multicolumn{3}{c}{ Customers } & \multicolumn{3}{c}{ Suppliers } \\
Cooperation Type & $(0)$ & $(1)$ & $(2)$ & $(0)$ & $(1)$ & $(2)$ \\
Estimated at probability & 0.215 & 0.424 & 0.360 & 0.227 & 0.355 & 0.418 \\
\hline Incoming Spillovers (generic) & 0.0225 & -0.0837 & 0.0612 & 0.0089 & -0.1600 & 0.1511 \\
& $(0.798)$ & $(0.434)$ & $(0.569)$ & $(0.921)$ & $(0.119)$ & $(0.177)$ \\
& -0.5242 & 1.2264 & -0.7022 & -0.4120 & -0.4230 & 0.8350 \\
Incoming Spillovers* (specific) & $(0.318)$ & $(0.068)$ & $(0.313)$ & $(0.160)$ & $(0.288)$ & $(0.098)$ \\
& -0.2729 & -0.0169 & 0.2898 & -0.2212 & 0.0063 & 0.2149 \\
Appropriability & $(0.000)$ & $(0.859)$ & $(0.004)$ & $(0.003)$ & $(0.944)$ & $(0.033)$ \\
& 0.0733 & -0.0737 & 0.0003 & 0.1360 & 0.2208 & -0.3567 \\
Legal Protection on Industry Level & $(0.855)$ & $(0.874)$ & $(0.999)$ & $(0.734)$ & $(0.613)$ & $(0.454)$ \\
& -0.1259 & -0.0748 & 0.2007 & -0.1189 & -0.0961 & 0.2150 \\
Existence of R\&D-Dept. (0/1) & $(0.004)$ & $(0.149)$ & $(0.000)$ & $(0.008)$ & $(0.050)$ & $(0.000)$ \\
& -0.1411 & 0.1641 & -0.0230 & -0.1072 & 0.0622 & 0.0451 \\
Continuous R\&D (0/1) & $(0.011)$ & $(0.007)$ & $(0.734)$ & $(0.028)$ & $(0.208)$ & $(0.425)$ \\
& -0.0007 & -0.2874 & 0.2882 & -0.0594 & -0.1390 & 0.1985 \\
Cost of R\&D & $(0.993)$ & $(0.004)$ & $(0.006)$ & $(0.439)$ & $(0.135)$ & $(0.065)$ \\
& 0.0468 & 0.0193 & -0.0661 & 0.0175 & 0.0866 & -0.1041 \\
Risk of R\&D & $(0.665)$ & $(0.887)$ & $(0.634)$ & $(0.828)$ & $(0.360)$ & $(0.319)$ \\
& -0.0183 & 0.0574 & -0.0391 & 0.0085 & -0.0986 & 0.0902 \\
Complementarities & $(0.781)$ & $(0.481)$ & $(0.633)$ & $(0.901)$ & $(0.204)$ & $(0.293)$ \\
& -2.2761 & 1.3253 & 0.9508 & -2.2215 & 0.8968 & 1.3246 \\
Innovation Dynamics on Industry Level & $(0.002)$ & $(0.115)$ & $(0.247)$ & $(0.004)$ & $(0.264)$ & $(0.128)$ \\
& -0.0353 & -0.0073 & 0.0427 & -0.0315 & -0.0015 & 0.0330 \\
Firm Size & $(0.002)$ & $(0.574)$ & $(0.001)$ & $(0.006)$ & $(0.906)$ & $(0.017)$ \\
& 0.0074 & 0.1317 & -0.1391 & -0.0345 & 0.1425 & -0.1080 \\
Firm is located in Eastern Germany $(0 / 1)$ & $(0.888)$ & $(0.047)$ & $(0.028)$ & $(0.346)$ & $(0.007)$ & $(0.033)$ \\
& & & & & &
\end{tabular}

Notes: Cooperation Types: (0) no cooperation; (1) informal cooperation; (2) formal cooperation and mixed cooperation modes.

* Variable Specific Incoming Spillovers results from an instrument variable estimation.

Values in brackets show probabilites of variables not to differ stochastically from zero (p-values).

For binary coded variables, the result expresses the impact of a discrete change of the variable from 0 to 1 
impact on the probability of choosing the 'no cooperation' strategy.

The probability of choosing the 'informal cooperation' strategy is not affected by a marginal increase in generic spillovers but there is weak empirical evidence that an increase in specific spillovers from customers has a positive impact on a firm's probability of cooperating informally with customers. A marginal increase in a firm's appropriability does not have a statistically significant impact on the decision to cooperate informally alone. Continuous $R \& D$ has a positive influence on informal cooperation with customers whereas the existence of a R\&D department and costs of R\&D have a negative effect. Furthermore, firms which are located in Eastern Germany have a higher probability of cooperating informally.

Next, we turn to a firm's probability of choosing the 'both modes of cooperation' strategy. Again generic spillover do not have a significant impact whereas the marginal effect of (specific) spillovers from customers is weakly significant. The marginal effect of appropriability is positive and statistically significant for cooperations with suppliers as well as for cooperations with customers. Firms with a R\&D department have a higher probability of cooperating formally with customer and suppliers. Moreover, costs of innovation have a positive and statistically significant marginal impact on a firm's decision to cooperate formally with customers and suppliers. Innovation risk and complementarities are statistically insignificant indicating that risk sharing and the availability of know-how within in a firm are not relevant drivers of formal and informal cooperations with vertically related firms. Firms in Eastern Germany have a lower probability of cooperating formally.

Discussion of Estimation Results. Our results provide only weak empirical evidence for a positive effect of spillovers from vertically related firms on formal cooperation ( $R \& D$ coordination) as suggested by the theoretical literature. There is some evidence that a firm's probability of choosing the 'both modes of cooperation' strategy with customers as well as a firm's willingness to share its technical knowledge with suppliers are affected by the relevance of these firms as external knowledge sources. The latter result would hint on the relevance of reciprocity for knowledge sharing. However, the statistical significance of the estimated effects of our specific spillover measure is rather weak and we have not found positive effects of specific spillovers on informal cooperations with customers and formal cooperations with suppliers. Although not reported here, we have performed estimations using various econometric specifications and the results suggest that the statistical significance of the estimated effect of the specific spillover measures is very sensitive. Moreover, 
our results show that the influence of the generic spillover measure is statistically insignificant which is in line with the finding reported by Cassiman and Veugelers (2002). Taken together, empirical results do not provide much empirical evidence for a positive impact of incoming spillovers on firms' cooperations with vertically related firms.

This result might explain why many firms in our sample choose to cooperate only informally (hence not formally) with their customers and suppliers, i.e. firms share their technical knowledge without coordinating their R\&D. From a theoretical point of view this would not be rational because formal cooperation (coordination of $\mathrm{R} \& \mathrm{D}$ ) allows cooperation partners to internalize these voluntary spillovers. Consequently, profits of the 'formal and informal cooperations strategy' would exceed profits of 'informal cooperation strategy'. ${ }^{14}$ However, internalization of spillovers does not seem to be the relevant reason for formal cooperations between customers and suppliers.

Appropriability seems to be a very relevant determinant for cooperation with vertically related firms. If a firm can effectively protect the rents from its product and process innovations through secrecy, complexity and lead time, it is significantly more likely that this firm is engaged into cooperative arrangements with its customers and suppliers. In particular, the probability of cooperating in both modes of cooperation is increased. There may be two explanations for this result: Firstly, cooperating firms do not fear that their technical knowledge leaks out to competitors because they are able to avoid the involuntary leakage of knowledge to non-partners. Secondly, cooperating firms are technology leaders in their market and produce complex products. Then, these firms may not have to fear that leakage of knowledge leads to an immediate imitation of their innovations by their competitors and in turn to an erosion of their profits. Cassiman et al. (2002) show that a leading technological firm has an incentive to make strategic investments to increase the complexity of the product or process design since this reduces the danger of imitation. In both cases, a high degree of effectiveness of strategic protection is something like a prerequisite for vertical cooperations. This means that 'strong' partners cooperate formally and informally while 'weak' ones do not. In contrast, legal protection (patents, copy-rights and brand names) does not seem to be relevant indicating that better appropriability conditions due to more effective legal protection of product and process innovations do not influence a firm's decision to cooperate formally or informally.

\footnotetext{
${ }^{14}$ Informal cooperations between customers and suppliers are not explicitly discussed by Atallah(2002) and Inkmann(2001) but profits of coordination of R\&D increase with vertical spillovers. The latter is equivalent to an increase in the transfer of technical knowledge.
} 
The firms' engagement in RED has an impact on cooperative behavior. Firms that perform R\&D continuously have a higher probability of cooperating with vertically related firms. This results may reflect the relevance of absorptive capacity for cooperation. Furthermore, our results show that the organizational structure of $R \mathcal{E} D$ seems to affect the choice of cooperation mode. Firms conducting R\&D continuously have a higher probability of cooperating informally whereas the existence of a R\&D department has no or a negative impact on the decision to cooperate informally. The results for formal cooperation are just the opposite. Here, the existence of a R\&D department has a positive and highly significant effect whereas continuous R\&D is statistically insignificant, once controlled for the existence of a R\&D department. Firms with own R\&D departments seem to have the organizational structure of R\&D which allows them to manage formal cooperation while others may not. This result suggests that formal cooperations are characterized by large overhead costs and therefore formal cooperation ( $R \& D$ coordination) may be associated with higher costs than informal cooperation (knowledge sharing). This interpretation is supported by our finding that firm size has a significant impact on a firm's decision to cooperate formally whereas the probability of cooperating informally is not affected by firm size. ${ }^{15}$

Innovation dynamics in an industry seem to be a relevant driver of cooperative arrangements for innovation since a high share of innovation expenditures for the development of new products and markets at the industry level leads to an increase in a firm's probability of cooperating formally and informally with customers and suppliers. This result may indicate that vertically related firms exchange their technical knowledge in order to reduce the risks associated with bringing a new product to the market or the implementation of new production technologies.

Furthermore, our results suggest that innovation costs have a positive impact on a firm's decision to cooperate formally with customers and suppliers while this is not the case for purely informal cooperations with vertically related firms. One might expect this since the informal exchange of technical knowledge is not designed to share costs. Thus, agreements to perform cooperative $R \& D$ (formal cooperation) seem to be preferred if customers and suppliers do not have an incentive to perform R\&D independently (von Hippel, 1987; p. 300). Such incentives may not exist because innovation costs are too high. Then, customers and suppliers may be engaged in formal cooperations in order to share innovation costs of large scale R\&D projects, e.g. costs for

\footnotetext{
${ }^{15}$ Note, that the logarithm of employees is used as an indicator for firm size. A positive coefficient implies a nonlinear, concave, relationship.
} 
laboratories, scientific instruments or office space.

\section{Conclusion}

We have investigated the determinants of cooperative arrangements for innovation between vertically related firms. Our estimation results suggest that appropriability, absorptive capacity, organizational structure of $R \& D$ and industries' innovation dynamics are relevant determinants of a firm's decision to cooperate.

Appropriability seems to be a key determinant for formal and informal cooperations with vertically related firms. A firm's ability to protect its proprietary innovations by protection mechanisms (appropriability), like secrecy, complexity and lead time, tends to increase the probability of cooperating with vertically related firms. In contrast, our estimation results do not provide much empirical evidence in support to the hypothesis that (incoming) spillovers between vertically related firms do have a positive impact on a firm's decision to cooperate. This extends the findings of previous work to informal cooperation. Moreover, we find that firms in industries with an intense development of new products and new markets (innovation dynamics) have a higher probability of cooperating formally and informally with customers and suppliers. Furthermore, firms' continuous engagement in R\&D, which may reflect absorptive capacity, seem to be relevant for cooperation.

Our results suggest that costs of cooperation may explain why the number of formal cooperations is considerably lower than the number of informal cooperations. Formal cooperative arrangements, like research joint ventures, are much more resource demanding than informal cooperations. Costs associated with formal modes of cooperation may work as a threshold for firms which are willing to engage in formal cooperations. Especially large firms engaged in large scale $R \& D$ projects which have own $R \& D$ departments are more likely to choose a mode of formal cooperation with vertically related firms. In contrast, informal cooperation allows for a flexible transfer of specific and commercially sensitive information, e.g. information about new product design, new production processes or market development, without writing and enforcing contracts.

Given the lack of theoretical literature on informal cooperations and the practical relevance of this mode of cooperation fruitful research can be expected

in the future. Theoretical studies could investigate the influence of knowledge protection on a firm's decision to cooperate informally. Another interesting 
point is the stability of informal exchange of knowledge. Which factors reduce or increase the incentives to defect from informal cooperation? Moreover, empirical studies on informal cooperations between horizontally related firms would be an interesting extension.

\section{References}

[1] Atallah, G. 2002. Vertical R\&D Spillovers, Cooperations, Market Structure, and Innovation. Economics of Innovation and New Technology 11, 179-202.

[2] Banerjee, S., Lin, P., 2001. Vertical research joint ventures. International Journal of Industrial Organization 19, 285-302.

[3] Cassiman, B., Veugelers, R., 2002. R\&D Cooperation and Spillovers: Some Empirical Evidence from Belgium. American Economic Review 92, 11691184.

[4] Cassiman, B., Pérez-Castrillo, Veugelers R., 2002. Endogenizing knowhow flows through the nature of R\&D investments. International Journal of Industrial Organization 20, 775-799.

[5] Cohen, W., Levinthal, D., 1989. Innovation and Learning: The Two Faces of R\&D. Economic Journal 99, 569-596.

[6] Colombo, M.G., Garrone, P., 1996, Technological cooperative agreements and firms' R\&D intensity. A note on causality relations. Research Policy 25, 923-932.

[7] D'Aspremont, C., Jacquemin, A., 1988. Cooperative and noncooperative R\&D in duopoly with spillovers. The American Economic Review 78, 1133-1137.

[8] DeBondt, R., 1996. Spillovers and innovative activities. International Journal of Industrial Organization 15, 1-28.

[9] Fritsch, M., Lukas, R., 2001. Who cooperates on R\&D?. Research Policy 30, 297-312.

[10] Greene, W.H., 2003. Econometric Analysis, 5th Edition, Prentice Hall.

[11] Griliches, Z., 1992. The Search for R\&D Spillovers, Scandinavian Journal of Economics 94, 29-47. 
[12] Grindley, P., Mowery, D., Silverman, B., 1994. SEMATECH and collaborative research: Lessons for the design of high technology consortia, Journal of Policy Analysis and Management 13, 723-758.

[13] Hagedoorn, J., Link, A.N. and N.S. Vonortas, 2000. Research Partnerships, Research Policy 29, 567-586.

[14] Harabi, N., 1998. Innovation through Vertical Relations between Firms, Suppliers and Customers: a Study of German Firms, Industry and Innovation 5, 157-179.

[15] Harhoff, D., 1996. Strategic spillovers and incentives for research and development. Management Science 42, 907-925.

[16] Hausman, J., McFadden, D., 1984. Specification Tests for the Multinomial Logit Model. Econometrica 52, 1219-1240.

[17] Hernán, R., Marín, P.L., Siotis, G., 2003. An Empirical Evaluation of the Determinants of Research Joint Venture Formation, The Journal of Industrial Economics 51, 75-89.

[18] Inkmann, J., 2001. Conditional moment estimation of nonlinear equation systems: with an application to an oligopoly model of cooperative R\&D, Berlin, Heidelberg, New York and London, Springer.

[19] Kaiser, U., 2002. An Empirical Test of Models Explaining Research Expenditures and Research Cooperation: Evidence for the German Service Sector. International Journal of Industrial Organization 20. 747-774.

[20] Kamien, M.I., Muller, E., Zang, I., 1992. Research joint venture and R\&D cartels. American Economic Review 82, 1293-1306.

[21] Kamien, M.I., Zang, I., 2000. Meet me halfway: research joint ventures and absorptive capacity. International Journal of Industrial Organization $18,995-1022$.

[22] Kultti, K., Takalo, T., 1998. R\&D spillovers and information exchange. Economics Letters 61, 121-123.

[23] Miotti, L., Sachwald, F., 2003. Co-operative R\&D: why and with whom? An integrated framework of analysis, Research Policy 32, 1481-1499.

[24] Schrader, S., 1991, Informal Technology transfer between firms: Cooperation through information sharing, Research Policy 20, 153-170. 
[25] Small, K.A., Hsiao, C., 1985. Multinomial Logit Specification Tests. International Economic Review 26, 619-627.

[26] Steurs, G., 1995. Inter-industry R\&D spillovers: What difference do they make? International Journal of Industrial Organization 13, 249-276.

[27] Tether, B.S., 2002. Who co-operates for innovation, an why - An empirical anlysis, Research Policy 31, 947-967.

[28] Von Hippel, E., 1987. Cooperation between rivals: Informal Know-How Trading, Research Policy 16, 291-302. 


\section{A Test results}

Table 4: Likelihood Ratio Test: Joint insignificance of coefficients associated with given variables

\begin{tabular}{lr|r} 
& Customers & Suppliers \\
& $\chi^{2}(2)$ & $\chi^{2}(2)$ \\
\hline Incoming Spillovers (generic) & 2.6410 & 0.6180 \\
& $(0.267)$ & $(0.734)$ \\
Incoming Spillovers* (specific) & 3.5120 & 3.4910 \\
& $(0.173)$ & $(0.175)$ \\
Appropriability & 9.3920 & 16.1250 \\
& $(0.009)$ & $(0.000)$ \\
Legal Protection on Industry Level & 0.5650 & 0.0410 \\
& $(0.754)$ & $(0.980)$ \\
Existence of R\&D-Dept. $(0 / 1)$ & 16.3970 & 15.9560 \\
& $(0.000)$ & $(0.000)$ \\
Continuous R\&D (0/1) & 6.6610 & 10.8870 \\
& $(0.036)$ & $(0.004)$ \\
Cost of R\&D & 3.4460 & 9.4770 \\
& $(0.179)$ & $(0.009)$ \\
Risk of R\&D & 1.1040 & 0.2930 \\
& $(0.576)$ & $(0.864)$ \\
Complementarities & 1.6930 & 0.4980 \\
& $(0.429)$ & $(0.779)$ \\
Innovation Dynamics on Industry Level & 8.8740 & 10.2070 \\
& $(0.012)$ & $(0.006)$ \\
Firm Size & 8.9060 & 14.8540 \\
& $(0.012)$ & $(0.000)$ \\
Firm is located in Eastern Germany $(0 / 1)$ & 9.5160 & 4.9310 \\
& $(0.009)$ & $(0.085)$
\end{tabular}

Notes: *Variable Specific Incoming Spillovers results from an instrument variable estimation. Values in brackets show probabilites of variables being jointly insignificant (p-values). 
Table 5: Wald-test of the Null that respective categories can be collapsed

\section{Customer}

\begin{tabular}{lr} 
Test & $\chi^{2}(12)$ \\
Informal vs. Mixed Mode & 66.477 \\
& $(0.000)$ \\
Informal vs. No cooperation & 53.189 \\
& $(0.000)$ \\
Mixed Mode vs. No cooperation & 127.770 \\
& $(0.000)$ \\
\multicolumn{1}{c}{ Supplier } & \\
& $\chi^{2}(12)$ \\
Test & 72.032 \\
Informal vs. Mixed Mode & $(0.000)$ \\
& 74.903 \\
Informal vs. No cooperation & $(0.000)$
\end{tabular}

Mixed Mode vs. No cooperation $\quad 128.026$

$(0.000)$ 
Table 6: Two tests for validity of the IIA assumption

Hausman Test for Customers

Omitted Cooperation Type $\quad \chi^{2}(13) \quad$ Evidence

(1)

2.127 for $H_{0}$

(1.000)

(2)

2.097 for $H_{0}$

(1.000)

Hausman Test for Suppliers

Omitted Cooperation Type

(1)

$\begin{array}{rr}\chi^{2}(13) & \text { Evidence } \\ -118.090 & \text { for } H_{0}\end{array}$

(一)

(2)

5.165 for $H_{0}$

$(0.971)$

Small-Hsiao Test for Customers

Omitted Cooperation Type $\quad \chi^{2}(13)$ Evidence

(1) 12.492 for $\mathrm{H}_{0}$

(0.488)

(2)

15.722 for $H_{0}$

$(0.264)$

Small-Hsiao Test for Suppliers

Omitted Cooperation Type $\quad \chi^{2}(13) \quad$ Evidence

(1)

13.109 for $H_{0}$

(0.439)

(2)

10.097 for $H_{0}$

(0.686) 